\title{
Vírus da Imunodeficiência Humana no contexto ambulatorial: desvelando o perfil e formas de transmissão
}

\author{
Human Immunodeficiency Virus in the outpatient setting: revealing the profile and forms of \\ transmission
}
Virus de Inmunodeficiencia humana en el contexto ambulatorio: desvelando el perfil y las formas de transmisión

Rebeca Coelho de Moura Angelim ${ }^{1 *}$, Brígida Maria Gonçalves de Melo Brandão ${ }^{1}$, Daniela de Aquino Freire $^{1}$, Denize Cristina de Oliveira², Sérgio Corrêa Marques², Fátima Maria da Silva Abrão .

\section{RESUMO}

Objetivo: Descrever, segundo a ótica de profissionais de saúde, as principais formas de transmissão do Vírus da Imunodeficiência Humana/Síndrome da Imunodeficiência Adquirida identificadas na prática diária e as mudanças do perfil das pessoas que vivem com o vírus. Métodos: Trata-se de estudo qualitativo, realizado com 46 profissionais de saúde. Para coleta de dados foi utilizada a técnica de entrevista semiestruturada. As falas foram gravadas, transcritas e analisadas por meio da técnica de análise de conteúdo lexical. O estudo foi aprovado por Comitê de Ética em Pesquisa. Resultados: Duas categorias foram apreendidas: formas de transmissão do vírus e mudanças no perfil de pessoas vivendo com o vírus, evidenciando uma substituição do conceito de grupos de risco pelo de vulnerabilidade. Conclusão: A principal forma de transmissão do vírus é por via sexual. A transmissão vertical e transfusão sanguínea também foram elencadas. Houve também uma mudança no perfil da doença, considerando que hoje qualquer pessoa que apresente comportamento de risco está vulnerável ao vírus.

Palavras-chave: Soropositividade para HIV, Perfil de saúde, Transmissão de doença infecciosa.

\begin{abstract}
Objective: To describe, according to the perspective of health professionals, the main forms of transmission of the Human Immunodeficiency Virus / Acquired Immunodeficiency Syndrome identified in daily practice and the changes in the profile of people living with the virus. Methods: This is a qualitative study, carried out with 46 health professionals. For data collection, the semi-structured interview technique was used. The statements were recorded, transcribed, and analyzed using the lexical content analysis technique. The study was approved by the Research Ethics Committee. Results: Two categories were apprehended: ways of transmitting the virus and changes in the profile of people living with the virus, evidencing a replacement of the concept of risk groups by that of vulnerability. Conclusion: The main form of transmission of the virus is through sex. Vertical transmission and blood transfusion were also listed. There was also a change in the profile of the disease, considering that today anyone who presents risky behavior is vulnerable to the virus.
\end{abstract}

Key words: HIV seropositivity, Health profile, Disease transmission infectious.

\section{RESUMEN}

Objetivo: Describir, de acuerdo con la perspectiva de los profesionales de la salud, las principales formas de transmisión del Virus de Inmunodeficiencia Humana / Síndrome de Inmunodeficiencia Adquirida identificado en la práctica diaria y los cambios en el perfil de las personas que viven con el virus. Métodos: Estudio cualitativo, realizado con 46 profesionales de la salud. Para la recolección de datos, se utilizó la técnica de entrevista semiestructurada. Las declaraciones fueron grabadas, transcritas y analizadas utilizando la técnica de análisis de contenido léxico. El estudio fue aprobado por el Comité de Ética de Investigación. Resultados: Se aprehendieron dos categorías: formas de transmitir el virus y cambios en el perfil de las personas que

${ }^{1}$ Universidade de Pernambuco (UPE), Recife - PE. *E-mail: rebecaangelim@hotmail.com

2 Universidade Estadual do Rio de Janeiro (UERJ), Rio de Janeiro - RJ. 
viven con el virus, evidenciando un reemplazo del concepto de grupos de riesgo por el de vulnerabilidad. Conclusión: La principal forma de transmisión del virus es a través del sexo. La transmisión vertical y la transfusión de sangre también se enumeraron. También hubo un cambio en el perfil de la enfermedad, teniendo en cuenta que hoy en día cualquiera que presente un comportamiento de riesgo es vulnerable al virus.

Palabras clave: Seropositividad para VIH, Perfil de salud, Transmisión de enfermedad infecciosa.

\section{INTRODUÇÃO}

O Vírus da Imunodeficiência Humana (HIV) causador da Síndrome da Imunodeficiência Adquirida (Aids) é um problema de saúde pública, pois trata-se de uma epidemia que atinge milhares de pessoas e que não tem cura. No Brasil, desde o início da epidemia até junho de 2019, foram registrados 966.058 casos de Aids (UNAIDS, 2016; BRASIL, 2019).

O panorama epidemiológico do HIV/Aids passou por mudanças ao longo do tempo, visto que no início da epidemia considerava-se que existiam grupos de risco, como por exemplo, o fato de ser profissional do sexo, homossexual do sexo masculino e/ou usuário de drogas injetáveis. No entanto, com o avanço dos estudos, hoje se sabe que qualquer pessoa está sujeita à infecção pelo HIV, pois as vulnerabilidades são de ordem social e individual e, independente de classe social, raça, idade ou opção sexual, todos estão expostos desde que não se tomem as devidas precauções (BANDEIRA AG, 2014).

Dessa forma, com vistas a garantir o diagnóstico precoce dos infectados e a disseminar as formas de prevenção aos não infectados, o processo de evolução da Aids no país refletiu sobre as instituições e os profissionais de saúde, fazendo com que importantes implicações para as políticas públicas e para a constituição de práticas profissionais de cuidado acontecessem (OLIVEIRA DC, 2013). Estas políticas possuem como foco principal oferecer uma assistência de qualidade às pessoas que vivem com HIV/Aids (VILLARINHO MV, et al., 2013).

Além dos serviços ofertados aos indivíduos soropositivos, ressalta-se também a terapia antirretroviral, que disponibiliza medicamentos para o tratamento do HIV/Aids de forma gratuita e universal. Entretanto, a epidemia da Aids no Brasil ainda é crescente, necessitando disponibilizar a toda população informações, medidas de prevenção e promoção da qualidade de vida (CARRAPATO J, et al., 2014).

Nessa perspectiva, considerando-se os avanços ocorridos ao longo das três últimas décadas da epidemia da Aids no Brasil, e suas transformações no âmbito epidemiológico, é preciso se ter noção das características da clientela, indo além de dados epidemiológicos e explorando o perfil e formas de transmissão pelo HIV que possivelmente sejam mais prevalentes e impactantes, tendo como base as memórias e experiências vividas por profissionais de saúde no cuidado prestado às pessoas com HIV/Aids ao longo de suas carreiras.

Com base no que foi exposto, este estudo teve como objetivo descrever, segundo a ótica de profissionais de saúde, as principais formas de transmissão do HIV/Aids identificadas na prática diária e as mudanças do perfil das pessoas que vivem com o vírus.

\section{MÉTODOS}

Estudo descritivo-exploratório, com abordagem qualitativa, desenvolvido em sete unidades de saúde que realizam atividades referentes ao Programa Nacional de Infecções Sexualmente Transmissíveis e Aids na cidade de Recife/Pernambuco, Brasil, sendo seis Serviços de Assistência Especializada em HIV/Aids e um Centro de Testagem e Aconselhamento (CTA).

A pesquisa ocorreu no período de fevereiro de 2012 a fevereiro de 2014, com participação de 46 profissionais de saúde, de nível técnico e superior, que atenderam aos seguintes critérios de inclusão: atividade profissional a partir do início da epidemia de HIV/Aids em Recife, atuação nos Serviços de Assistência Especializada em HIV/Aids ou CTA selecionados no período da coleta de dados. Foram excluídos os profissionais que estivessem de férias ou de licença no período da coleta de dados. A seleção da amostra se deu através de um mapeamento sobre a quantidade de profissionais atuantes em cada serviço e, 
posteriormente, por meio do critério de saturação dos dados. Vale ressaltar também que alguns participantes se recusaram e outros desistiram durante a entrevista.

A coleta de dados foi realizada com a utilização de entrevista semiestruturada realizada a partir de um roteiro temático que extraiu informações das formas de contaminação pelo HIV e relacionadas ao perfil das pessoas com HIV/Aids no início da epidemia e atualmente, de acordo com experiências e histórias de pacientes que estes profissionais de saúde puderam acompanhar ao longo de suas carreiras.

As entrevistas ocorreram nos locais de serviço dos profissionais e foram gravadas, transcritas e organizadas, preservando a identidade dos sujeitos, sendo eles identificados pelo código alfanumérico $E$ (que significa entrevista), o número da entrevista e a profissão de cada um (Exemplo: E1, enfermeira).

Para análise dos dados resultantes das entrevistas foi utilizada a técnica de análise de conteúdo lexical, com o auxílio do software Analyse Lexicale par Context d'un Ensemble de Segments de Texte. Nessas análises foram desenvolvidas descrições detalhadas e aprofundadas dos conteúdos das falas. O software gerou classes, que foram subdivididas em blocos.

O processamento no software resultou na formação de cinco classes divididas em dois blocos, no qual o primeiro está relacionado ao contexto histórico e social da Aids e o segundo bloco concentra informações sobre as práticas de cuidado dos profissionais de saúde no contexto da assistência às pessoas com HIV/Aids.

Neste estudo será abordada apenas a classe cinco, presente no primeiro bloco, referente à infecção e exposição ao HIV/Aids. Para uma melhor compreensão dessa classe, será descrito a seguir duas categorias: 1 - Formas de transmissão do HIV; 2 - Mudanças no perfil de pessoas vivendo com HIV/Aids.

O estudo respeitou as exigências formais contidas nas normas nacionais e internacionais regulamentadoras de pesquisas envolvendo seres humanos, tendo sido aprovado pelo Comitê de Ética e Pesquisa da Universidade de Pernambuco sob Parecer no $125-\mathrm{A} / 11$.

\section{RESULTADOS}

Dos 46 participantes, a maioria foi do sexo feminino $(76,1 \%)$, pertencentes à faixa etária de 41 a 50 anos $(39,1 \%)$, de religião católica $(43,5 \%)$, vivendo com companheiro $(56,5 \%)$ e com pós-graduação lato sensu $(52,2 \%)$. Participaram do estudo médicos, enfermeiros, técnicos de enfermagem, psicólogos, farmacêuticos, assistentes sociais e nutricionistas.

\section{Categoria 1: Formas de contaminação pelo HIV}

Percebeu-se que em relação às formas de contaminação pelo HIV, a que ocorre por meio da relação sexual desprotegida foi evidenciada pela maioria das falas, como exposto a seguir:

"Eu me lembro de um cara que nos primeiros meses em que eu estava aqui tinha um namorado. O namorado tinha HIV e ele não. Quando o atendia, revelou-me que às vezes usava preservativo e outras não" (E16, psicóloga).

"Não é que se tenha que viver com o medo, mas saber que com a informação devida ele pode ter uma vida normal, desde que se cuide. Porque eu acho que com os métodos de hoje não se justifica dizer que engravidou acidentalmente e pegou HIV acidentalmente por relação sexual, a não ser por desleixo ou por uma infelicidade muito grande de um preservativo romper" (E27, dentista).

"Teve um rapaz, adolescente, de catorze anos que morreu. Ele se envolveu com uma mulher mais velha, mulher que já tinha tido alguns parceiros e ele já sabia de tudo isso. Se envolveu com uma mulher bem mais experiente e, nessa fantasia toda, ele morreu" (E18, técnico de enfermagem).

É comum também observar as transmissões sexuais do HIV decorrentes de relações extraconjugais do cônjuge, conforme evidenciado a seguir: 
"Meu maior trabalho é com gestante. Foi uma das primeiras que disse para mim que pegou HIV com o marido e que já tinha comprado chumbinho para matar ele" (E33, médico).

"Teve um que tinha um histórico de bissexualidade. E a preocupação maior (dele) era a noiva e ele a contaminou" (E25, enfermeira).

"E há depoimentos que eu já ouvi de homossexuais que têm relações com homens casados. E são relações muito loucas, pelos depoimentos que eu ouvi" (E18, técnica de enfermagem).

Ademais, ainda em relação à infecção decorrente de relações do companheiro fora do casamento, os participantes consideram a mulher traída como vítima:

"Ela adquiriu por falta de responsabilidade. Às vezes a pessoa pega e não depende dela. Às vezes a pessoa é casada e tem um marido que sai com outras pessoas e ela não sabe" (E12, técnico de enfermagem).

"É diferente daquela mulher que até os profissionais de saúde na grande maioria tratam como coitada. Ela foi infectada pelo marido. Aquela história inicial. Aí não vem muita culpa, vem muita pena" (E1, assistente social).

"Uma história que não me saía da mente é a história de uma jovem que se casou. Foi o primeiro relacionamento dela e ela se descobre HIV positiva a partir do diagnóstico do marido, que vinha adoecendo" (E1, assistente social).

"O segundo é esposa que se infecta com seu marido. Ainda há a ideia de que as mulheres são vítimas dos homens” (E22, psicólogo).

"Essa pessoa não merecia ser contaminada e através disso vem a questão dos filhos. O filho foi contaminado devido a ele. Ele sabia. Usando a sua consciência, acabou gerando um prejuízo maior, porque contaminou a mãe, contaminou o filho, os quais vão precisar entrar num programa para fazer antirretrovirais que não haveria necessidade" (E38, enfermeira).

Em contraponto, um profissional considerou que dependendo da situação, a mulher não é vítima:

"Quando você pega crianças que contraem HIV por transfusão de sangue, para a sociedade elas são vítimas. Com relação às mulheres que pegaram de seus maridos, fica meio ambivalente; alguns acham que é vítima, e outros acham que não, porque se eu sei que meu marido é 'galinha', supõe-se que eu sabia do risco que eu estava correndo" (E45, psicóloga).

Outras formas de transmissão relatadas foram por meio da transmissão vertical e da transfusão sanguínea:

"Foi quando eles descobriram que não era só o homossexual que se contaminava com o HIV, quando começaram a nascer crianças e aparecer mulheres HIV positivo" (E17, técnico de enfermagem).

"Por exemplo, uma criança quando ela é infectada via transmissão vertical, pode ser que a mãe nem sequer soubesse que ela estava infectada, e ela transmitiu o HIV ao filho. Não é porque ela queria" (E34, psicóloga).

"Então, eu soube depois que ele foi transplantado. Ela doou um rim para ele. Foi aí que ela descobriu e ele pegou o HIV com ela" (E31, enfermeira).

"É tão interessante quando usa a palavra vítima. Ainda em relação à infecção pelo HIV por via sanguínea, um participante afirmou que independente da forma que se contrai, o estigma sempre estará presente. Eu tenho uma paciente HIV positiva que 
pegou o HIV em transfusão sanguínea e ela é estigmatizada do mesmo jeito" (E24, enfermeira).

\section{Categoria 2: Mudanças no perfil de pessoas vivendo com HIV/Aids}

Quando indagados sobre como era o perfil das pessoas que vivem com HIV/Aids no início da epidemia, houve os seguintes relatos:

"O perfil é classe média baixa, o percentual maior. Antes eram mais homens homossexuais. Agora são senhoras, mulheres" (E2, nutricionista).

"Antigamente existiam os grupos de risco, que eram homossexuais, profissional do sexo e pessoas com tatuagem, usuário de droga injetável. Isso era muito veiculado na sociedade" (E14, técnica de enfermagem).

"Predominantemente usuário de drogas, homossexuais, profissional do sexo, entre outras. Remetia ao perfil majoritariamente masculino e a essa questão da magreza extrema" (E42, assistente social).

"Eram mais homens. Era toda idade, só que mais jovens" (E10, técnica de enfermagem).

"Na verdade, a maioria das pessoas com HIV/Aids que aparecia para nós aqui no início eram muitas pessoas com HIV/Aids do sexo masculino, muitos homossexuais, faixa etária trinta a quarenta anos, mais ou menos" (E35, farmacêutica).

"Antigamente tinha pessoas que viajavam, que iam à Europa, Estados Unidos, pessoas que viajavam muito para o exterior" (E17, técnico de enfermagem).

"Inicialmente, tinha as crianças de transmissão vertical, mãe e filho, mas também um grande contingente de crianças e adolescentes com infecção por hemotransfusão" (E36, médico).

"As mulheres eram raríssimas, os homens predominavam esmagadoramente, principalmente os homossexuais masculinos e isso ajudou muito a reforçar 0 preconceito e, ainda, era uma doença de classe média para cima, era uma doença de quem viajava para fora" (E8, médico).

"Antigamente, a faixa etária predominante era mais ou menos dos vinte e cinco aos trinta e cinco anos de idade. E era mais usuário de droga e por relação sexual anal, pois eram os pacientes homossexuais" (E13, técnica de enfermagem).

Diante das falas ilustradas, no início da epidemia da Aids, o perfil das pessoas contaminadas era caracterizado por serem homens homossexuais, usuários de drogas, profissionais do sexo e indivíduos de classe média ou alta.

No que tange o perfil das pessoas com HIV/Aids na atualidade, seguem algumas falas em que os profissionais de saúde revelam tal realidade:

"Atinge, atualmente, pessoas de todas as classes sociais, econômicas, homens, mulheres, e não só esposa que pega com marido dentro de casa, mas também com outros parceiros sexuais, com outras pessoas fora de casa" (E20, médica).

"Eu trabalho com gestante HIV. Essas são as mais vítimas, as mulheres de bissexuais e de homens promíscuos que pegam HIV" (E6, médico).

"É mais mulher, criança, pessoas em idade fértil, pobre e o pessoal do interior se contaminando" (E24, enfermeira). 
"Isso melhorou muito, mas ainda continua sendo extremo, a visão continua sendo preconceituosa no sentido de que o HIV positivo é, em sua maioria, homossexual, promíscuo, usuário de droga ou uma pessoa que é julgada duramente" (E8, médico).

"Atualmente não acontece caso de contaminação por transfusão. Acho que o último caso que eu saiba em Pernambuco acho que foi na década de 90. Não houve mais caso de contaminação por transfusão. Quase não acontece mais a transmissão vertical, que é quando a mãe transmite HIV para o filho" (E17, técnico de enfermagem).

\section{DISCUSSÃO}

A principal forma de transmissão do HIV é por meio da relação sexual desprotegida. Isso se deve, pelo baixo uso consciente do preservativo, que pode estar associado à possibilidade de diminuição do prazer e pode também ser potencializado quando acompanhado de uso de álcool (LEDDY AM, et al., 2018; PATRICECOY C, et al., 2016; PAPAS RK, et al., 2018).

Além disso, cada vez mais a população mais jovem está iniciando a vida sexual de forma precoce e muitas vezes sem o uso de preservativo, que pode ser parcialmente compensado pelo uso de anticoncepcional entre mulheres, aumentando sua vulnerabilidade sexual às Infecções Sexualmente Transmissíveis (IST), ao vislumbrar apenas a prevenção de gravidez e consequentemente contribuindo no aumento do sexo desprotegido (LANTOS H, et al., 2018).

Estudo revela que o nível de comunicação, o monitoramento da conduta e a proximidade de familiares desempenham um papel muito importante na prevenção de comportamento sexual de risco em adolescentes (LAVIELLE-SOTOMAYOR P, et al., 2014).

A infecção pelo HIV não é uma consequência inevitável da exposição ao vírus. A taxa estimada de aquisição da infecção para cada 10.000 exposições sexuais é de 138 por sexo anal receptivo e oito através de sexo vaginal receptivo. O risco de transmissão é maior em presença de outras infecções sexualmente transmissíveis, infecção aguda ou muito avançada pelo HIV e carga viral plasmática elevada. Por outro lado, o risco é menor quando é usado preservativo ou quando o ato sexual envolve indivíduo circuncidado (SCHECHTER M, 2016; BECERRA JC, et al., 2016).

Concomitantemente, uma pesquisa realizada nos Estados Unidos da América revelou que a proporção de novas infecções por HIV é maior em homens que fazem sexo com homens e que apenas $16 \%$ destes, relataram uso consistente de preservativo durante a relação sexual com seu parceiro HIV positivo (SMITH DK, et al., 2015).

Outro motivo que contribui para a disseminação do vírus são as relações extraconjugais. Para os profissionais está claro que a transmissão sexual se dá, em maior parte, em casos onde o homem trai a sua companheira, e essa infidelidade pode ocorrer tanto com mulher quanto com outro homem, não estando presente na maioria das relações sexuais a proteção, favorecendo, assim, a disseminação do vírus.

A mulher se apresenta numa conjuntura de vulnerabilidade para se contaminar com o HIV, pois é como se o casamento ou a relação estável representassem amor e respeito, levando-a a um estado de confiança e fidelidade ao parceiro, o que pode ocasionar a inexigência do uso do preservativo (FIGUEIREDO LG, et al., 2013; MUGWENI E, et al., 2014).

Esta situação é preocupante, tanto que repercutiu na mudança do perfil epidemiológico, uma vez que aumentou o número de casos entre os heterossexuais, sobretudo entre mulheres casadas (VILLARINHO MV e PADILHA MI, 2014; MADIBA S e NGWENYA N, 2017).

Desta forma, a contaminação decorrente de um envolvimento extraconjugal por parte do cônjuge pode acabar levando a esposa a uma posição de vítima. Porém, ressalta-se que não se pode generalizar, pois a infidelidade pode partir de ambos os lados. 
Sobre este aspecto, percebe-se a importância em realizar intervenções entre casais sorodiscordantes para estimular, durante seu primeiro ano de relacionamento, a divulgação do status sorológico com o parceiro, a fim de diminuir a transmissão do HIV, incentivar o tratamento e o apoio (MBICHILA TH, et al., 2018).

Ainda em relação às formas de contaminação pelo HIV, têm-se também por meio de transmissão vertical. No início da epidemia, se pensava que mulheres e crianças não tinham chances de ter HIV, porém com o aparecimento dos primeiros casos essa concepção foi desfeita. Outra problemática é a de que quando a criança contrai HIV por transmissão vertical, muitas vezes não foi por culpa da mãe, visto que, em muitos casos, nem a própria mãe sabia que tinha o vírus. Nesse contexto, os profissionais acabam se solidarizando com esta situação.

Em contrapartida, em um estudo, a gestação no contexto do HIV foi vista pela maioria dos profissionais de saúde como relacionada à irresponsabilidade. Nesses casos, tal opinião pode decorrer em um cuidado não humanizado e que não se volte para as necessidades psicológicas e sociais neste momento da vida da mulher, sendo as condutas limitadas a procedimentos técnicos (CALDAS MA, et al., 2015).

Cabe destacar que a eliminação completa da transmissão vertical é viável em um país de alta renda e baixa prevalência. Isso requer uma triagem universal e contínua no início da gravidez e acesso fácil à terapia antirretroviral a todas as pessoas soropositivas (AHO I, et al., 2018).

Há também a infecção pelo HIV através de transfusão. Sabe-se que no início da epidemia não existia uma política efetiva do controle de sangue e hemoderivados nos hemocentros. Nesse ínterim, muitas pessoas contraíram HIV por transfusão, pois na época não se realizava testes no sangue, já que a Vigilância Sanitária não atuava nesta área de controle (VILLARINHO MV e PADILHA MI, 2014). Hoje, os testes no sangue fazem parte do dia a dia de todo hemocentro e, embora ainda exista o risco de contaminação por transfusão sanguínea, este é consideravelmente menor se comparado ao início da epidemia.

No início da epidemia, era veiculado na imprensa imagens de pessoas debilitadas, associando-as à morte e, além disso, por falta de estudo e informações sobre a doença, foi reforçado no imaginário coletivo que a Aids estava presente apenas em grandes centros urbanos e fruto de condutas sociais reprováveis, praticadas por profissionais do sexo, usuários de drogas injetáveis e homossexuais (BANDEIRA AG, 2014; HOEFINGER H e SRUN S, 2017). Vê-se que a limitação de pesquisas médicas na época fez com que se disseminassem concepções errôneas a respeito do perfil da doença, limitando-a a determinado grupo.

Porém, o perfil da doença mudou. Agora, entende-se que o correto não é utilizar a expressão grupo de risco, mas sim o conceito de vulnerabilidade, visto que nos últimos tempos, tem-se percebido um aumento da incidência do HIV em pessoas de ambos os sexos e que estão em relacionamentos estáveis, mulheres, pessoas com baixos índices de escolaridade e renda, e em zonas menos urbanizadas, ocorrendo uma tendência para o processo de heterossexualização, feminização, pauperização e interiorização do HIV/Aids (SILVA RA, et al., 2016).

Ainda que o perfil sociodemográfico atual das pessoas com HIV/Aids tenha passado por mudanças, até hoje alguns profissionais ainda remetem às características identificadas no início da epidemia, demonstrando que embora muita coisa tenha sido desmistificada, alguns conceitos culturalmente enraizados pela sociedade ainda se fazem presentes.

Como forma de modificar este cenário, é sabido que as políticas públicas são de grande valia na promoção, prevenção e cuidado às pessoas com HIV/Aids, pois além do seu objetivo de prestar uma assistência de qualidade, também são importantes ferramentas de combate as discriminações voltadas a esses indivíduos (ZUCCHI EM, et al., 2013). Sendo assim, as ações propostas por essas políticas merecem ser seguidas pelos profissionais de saúde e divulgadas pela mídia como uma forma de esclarecer a população e diminuir 0 estigma que desde sempre permeou o HIV/Aids (KONTOMANOLIS EM, 2017).

Como limitação deste estudo destaca-se a impossibilidade de generalização dos resultados pelo fato da amostra ser restrita, em virtude do método utilizado, que foi o qualitativo. No entanto, apesar do número amostral reduzido, o software utilizado permite uma análise profunda das falas, tornando-a eficaz.

\section{CONCLUSÃO}

REAS/EJCH | Vol.12(10) | e4497 | DOI: https://doi.org/10.25248/reas.e4497.2020 Página 7 de 8 
O presente estudo identificou que a principal forma de transmissão do HIV é pela via sexual e evidenciou que muitas vezes está associada a algum relacionamento extraconjugal, onde um dos cônjuges se infecta com outra pessoa fora de casa e acaba transmitindo para o(a) companheiro(a). Além disso, a transmissão vertical e a transfusão sanguínea também foram elencadas. Em relação ao perfil da doença no início da epidemia e nos dias atuais, vê-se que segundo as falas houve uma mudança, onde a princípio o perfil era relacionado aos considerados grupos de risco (homossexuais, profissionais do sexo, usuários de drogas injetáveis) e que hoje, após três décadas da epidemia, se sabe que toda pessoa está vulnerável ao HIV, desde que apresente comportamentos de risco.

\section{REFERÊNCIAS}

1. PROGRAMA CONJUNTO DAS NAÇÕES UNIDAS SOBRE HIV/AIDS (UNAIDS). Estatísticas. 2016.

2. BRASIL. Ministério da Saúde. Secretaria de Vigilância em Saúde - Departamento de DST, Aids e Hepatites Virais. Boletim Epidemiológico - Aids e DST. Ano V - no 1. Brasília: Ministério da Saúde; 2019.

3. BANDEIRA AG. O envelhecimento e a prevenção do HIV/AIDS: um desafio para os profissionais de saúde. Ciênc Saúde. 2014; 7(3): 115.

4. OLIVEIRA DC. Construction and transformation of social representations of aids and implications for health care. Rev Latino Am Enfermagem. 2013; 21(Spec): 276-86.

5. VILLARINHO MV, et al. Políticas públicas de saúde face à epidemia da AIDS e a assistência às pessoas com a doença. Rev Bras Enferm. 2013; 66(2): 271-7.

6. CARRAPATO J, RESENDE MH, SANTOS NO. Pessoa vivendo com HIV/AIDS: diagnóstico de uma sentença de morte? Emancipação. 2014; 14(2): 321-36.

7. LEDDY AM, et al. Adapting the risk environment framework to understand substance use, gender-based violence, and HIV risk behaviors among female sex workers in Tanzania. AIDS Behav. 2018; 22(167): 1-11.

8. PATRICE-COY C, JOHNSON EJ, BOODRAM CA. Sexual behavior of female adolescents on the spread of HIV/AIDS and other STDs in Carriacou. Medicine (Baltimore). 2016; 95(36): e4800.

9. PAPAS RK, et al. Associations with unprotected sexual behavior among HIV-infected drinkers in Western Kenya. AIDS Behav. 2018; 22(167): 1-11.

10. LANTOS H, BAJOS N, MOREAU C. Determinants and correlates of preventive behaviors at first sex with a first partner and second partner: analysis of the FECOND Study. J Adolesc Health. 2018; 58(6): 644-51.

11. LAVIELLE-SOTOMAYOR $P$, et al. The impact of family characteristics in sexual risk behaviour of teens. Rev Med Inst Mex Seguro Soc. 2014; 52(1): 38-43.

12. SCHECHTER M. Profilaxia pré e pós-exposição: o uso de drogas antirretrovirais para a prevenção da transmissão sexual da infecção pelo HIV. BJID Educ Méd Contin. 2016; 2(4): 112-7.

13. BECERRA JC, BILDSTEIN LS, GACH JS. Recent insights into the HIV/AIDS pandemic. Microb Cell. 2016; 3(9): 45175.

14. SMITH DK, et al. Condom effectiveness for HIV prevention by consistency of use among men who have sex with men in the United States. J Acquir Immune Defic Syndr. 2015; 68(3): 337-44.

15. FIGUEIREDO LG, et al. Perception of married women about the risk of HIV infection and preventive behavior. Rev Enferm UERJ. 2013; 21(spe.2): 805-11.

16. MUGWENI E, OMAR M, PEARSON S. Understanding barriers to safer sex practice in Zimbabwean marriages: implications for future HIV prevention interventions. Health Educ Res. 2014; 30(3): 388-99.

17. VILLARINHO MV, PADILHA MI. Percepção da aids pelos profissionais da saúde que vivenciaram a epidemia durante o cuidado prestado às pessoas com a doença, em Florianópolis-SC, Brasil (1986-2006). Ciênc Saúde Coletiva. 2014; 19(6): 1951-60.

18. MADIBA S, NGWENYA N. Cultural practices, gender inequality and inconsistent condom use increase vulnerability to HIV infection: narratives from married and cohabiting women in rural communities in Mpumalanga province, South Africa. Glob Health Action. 2017; 10(Suppl.2): 55-62.

19. MBICHILA TH, et al. Partnership duration and HIV serodisclosure among people living with HIV/AIDS in Lilongwe, Malawi. Int J STD AIDS. 2018; 29(6): 956462418769730.

20. CALDAS MA, et al. Perception of the nursing team on pregnancy concerning infection caused by HIV. Rev Rene. 2015; 16(1): 29-37.

21. AHO I, et al. Comprehensive nationwide analysis of mother-to-child HIV transmission in Finland from 1983 to 2013. Epidemiol Infect. 2018; 146(7): 1-7.

22. HOEFINGER H, SRUN S. "At-risk" or "Socially deviant"? Conflicting narratives and grassroots organizing of sex/entertainment workers and LGBT communities in Cambodia. Soc Sci. 2017]; 6(3): 93.

23. SILVA RA, et al. Clinical-epidemiological profile of hiv-positive adults attended in a hospital from Natal/RN. Rev Fund Care Online. 2016; 8(3): 4689-96.

24. ZUCCHI EM, et al. Intervenções para reduzir o estigma da Aids no Brasil: uma revisão crítica. Temas Psicol. 2013; 21(3): 1067-87.

25. KONTOMANOLIS EM, et al. The social stigma of HIV-AIDS: society's role. HIV AIDS (Auckl). 2017; 9: 111-8. 